\title{
Planejamento participativo na infância: experiência inovadora de promoção da saúde na formação superior
}

\author{
Participatory planning with children: innovative experience of health promotion in higher \\ education \\ Planificación participativa con niños: experiencia innovadora en promoción de la salud en \\ educación superior
}

Luan dos Santos Fonseca

ORCID: https://orcid.org/0000-0002-2981-7327 Universidade Federal de Sergipe, Brasil

E-mail: luan-fonseca@ hotmail.com

Murilo Correzola Pinto

ORCID: https://orcid.org/0000-0003-1691-0538 Universidade Federal de Sergipe, Brasil

E-mail: mcorrezola@hotmail.com

Josielma dos Santos Costa

ORCID: https://orcid.org/0000-0002-1404-9417 Universidade Federal de Sergipe, Brasil

E-mail: josielmasantoscosta@outlook.com

Beatriz Correia Carvalho

ORCID: https://orcid.org/0000-0002-1930-224X Universidade Federal de Sergipe, Brasil

E-mail: becorreia97@gmail.com

José Cleyton de Oliveira Santos

ORCID: https://orcid.org/0000-0001-5616-7625 Universidade Federal de Sergipe, Brasil E-mail: cleyton-121@hotmail.com

Laíse Luemmy de Lima Ferreira ORCID: https://orcid.org/0000-0002-8609-6108 Universidade Federal de Sergipe, Brasil E-mail: laiseluemmy.98@gmail.com

Marcelo Santos de Araujo ORCID: https://orcid.org/0000-0003-0469-7012 Universidade Federal de Sergipe, Brasil

E-mail: marcelo.fisioterapeuta@outook.com

Rafael Nascimento Santos ORCID: https://orcid.org/0000-0003-0384-9053 Universidade Federal de Sergipe, Brasil E-mail: rafael.san.94064@gmail.com

Bruno Correia Carvalho ORCID: https://orcid.org/0000-0003-4936-406X

Universidade Tiradentes, Brasil

E-mail: bruno.unitenf2@gmail.com

Karla Yasmim de Andrade Santana ORCID: https://orcid.org/0000-0002-5085-4632

Universidade Federal de Sergipe, Brasil

E-mail: karlayasmim28@gmail.com

Márcia Schott

ORCID: https://orcid.org/0000-0002-9825-883X

Universidade Federal de Sergipe, Brasil E-mail: marciaschott@hotmail.com

Renata Jardim

ORCID: https://orcid.org/0000-0003-2760-3664 Universidade Federal de Sergipe, Brasil E-mail: renatajardim.m@gmail.com

\section{Resumo}

O Sistema Único de Saúde (SUS) atende à população a partir dos princípios de universalidade, integralidade e igualdade. Portanto, ações de Promoção de Saúde (PS), como um processo de capacitação da comunidade para atuar 
na melhoria de sua qualidade de vida, são de extrema importância para a consolidação do SUS. Nesse sentido, este estudo tem como objetivo relatar a experiência de acadêmicos da área da saúde, da Universidade Federal de Sergipe, na aplicação de um instrumento de mobilização popular (Método Bambu), com enfoque na PS, realizado com o público infantil (de 5 a 8 anos), em uma escola no interior do município de Lagarto-Sergipe, Brasil. Foram realizadas duas oficinas com a participação de 26 crianças. Observou-se incentivo à autonomia individual, com foco na consolidação do empoderamento; à compreensão; à reflexão da realidade em que as crianças estão inseridas; despertamento de atores locais; altruísmo e realização de trabalhos para a coletividade. Concluiu-se que o trabalho coletivo e participativo possibilitou às crianças a consciência de seu papel social e sua relevância como sujeitos que podem realizar mudanças na comunidade. Evidenciou-se, também, efeitos positivos na formação profissional em saúde dos acadêmicos responsáveis pelo projeto.

Palavras-chave: Promoção da saúde; Educação infantil; Empoderamento para a saúde; Planejamento participativo.

\begin{abstract}
The Unified Health System (SUS) serves the population based on the principles of universality, integrality and equality. Therefore, Health Promotion (HP) actions, as a process of empowering the community to act upon the improvement of their quality of life, are extremely important for the consolidation of SUS. Hence, this study aims to report the experience of health students, from the Federal University of Sergipe, in the application of an instrument of popular mobilization (Bambu Method), with a focus on HP, carried out with children (from 5 to 8 years old), in a school at the countryside of Lagarto-Sergipe, Brazil. Two workshops were held, attended by 26 children. It was observed encouragement to individual autonomy, aiming the consolidation of empowerment; and the awareness of the reality in which children are inserted. It also stimulated the awakening of local actors; altruism and the accomplishment of works for the collectivity. In conclusion, the manual collective work allowed the children the necessary cousciousness and autonomy to understand their social role and their importance as subjects that can make changes in the community. There were also positive effects on the professional health formation of the academics responsible for the project.
\end{abstract}

Keywords: Health promotion; Child rearing; Empowerment for health; Participative planning.

\title{
Resumen
}

El Sistema Único de Salud (SUS) atiende a la población con base en los principios de universalidad, integralidad e igualdad. Por tanto, las acciones de Promoción de la Salud (PS), como proceso de formación de la comunidad para actuar en la mejora de su calidad de vida, son de suma importancia para la consolidación del SUS. En este sentido, este estudio tiene como objetivo reportar la experiencia de académicos del área de la salud, de la Universidad Federal de Sergipe, en la aplicación de un instrumento de movilización popular (Método Bambu), con enfoque en PS, realizado con el público infantil (de 5 a 8 años), en una escuela del interior del municipio de Lagarto-Sergipe, Brasil. Se realizaron dos talleres con la participación de 26 niños. Se incentivó la autonomía individual, con un enfoque en la consolidación del empoderamiento; comprensión; reflexionar sobre la realidad en la que se insertan los niños; despertar de los actores locales; altruismo y trabajo para la comunidad. Se concluyó que el trabajo colectivo y participativo permitió a los niños tomar conciencia de su rol social y su relevancia como sujetos que pueden generar cambios en la comunidad. También hubo efectos positivos en la formación profesional en salud de los académicos responsables del proyecto.

Palabras clave: Promoción de la salud; Crianza del niño; Empoderamiento para la salud; Planificación participativa.

\section{Introdução}

O Sistema Único de Saúde (SUS) é um dos maiores e mais complexos sistemas de Saúde Pública do mundo, criado a partir da Constituição Federal de 1988 (Duarte, Eble, \& Garcia, 2018). Tem como objetivo atender a toda população brasileira, de acordo com os princípios da universalidade, integralidade e igualdade, a fím de garantir atenção, cuidado e vigilância a todos os níveis de atenção à saúde (Duarte, Eble, \& Garcia, 2018; Teixeira, Costa, Carmo, Oliveira, \& Penna, 2018). No entanto, nota-se que as ações do SUS ainda possuem foco no modelo médico hegemônico, dando sempre mais enfoque à doença e ao tratamento do que à promoção e à prevenção de saúde (Teixeira, Costa, Carmo, Oliveira, \& Penna, 2018).

Uma das estratégias adotadas pelo SUS é a Atenção Primária à Saúde (APS). Ela foi mencionada pela primeira vez na Conferência de Alma-Ata (1978) e deve ser guiada pela realidade sanitária da comunidade para a realização de ações preventivas, curativas e de Promoção de Saúde (PS) (Declaração de Alma-Ata sobre cuidados primários, 1978). Nesse prisma, a disseminação de informações permite que o sujeito busque maior participação em ações ligadas à saúde, adotando capacidade crítica para as questões da Saúde Pública (Campos, Minayo, Akermam, Drumond Júnior, \& Carvalho, 2006). A 
APS é de extrema importância para o sistema público de saúde, pois possui grande eficácia com baixo custo financeiro (Campos, Minayo, Akermam, Drumond Júnior, \& Carvalho, 2006; Starfield, 1994; Starfield, 2002).

Dentro da perspectiva da Promoção da Saúde, encontra-se o Projeto Municípios Saudáveis, que tem como proposta a melhoria ambiental e social de uma comunidade, a partir das suas potencialidades (Sá et al, 2007; Santana, Galvão, Costa, \& Tavares, 2016). Uma das ferramentas utilizadas a fim de impulsionar essas faculdades é o Método Bambu (MB), que busca trabalhar coletivamente ações de PS, a partir da solidariedade e da cooperação coletiva. Demonstra ser um trabalho gradativo, que tem muita força e ao mesmo tempo flexibilidade e versatilidade para adaptar-se à dinâmica social presente. Ele tem como objetivo, por meio da participação popular, a autonomia e a melhoria da qualidade de vida de uma população (Sá et al, 2007, Santana, Galvão, Costa, \& Tavares, 2016; Moysés \& Franco, 2014).

No MB, estimula-se a participação e, para que seja efetiva, é necessário que o indivíduo exerça sua autonomia e empoderamento (tenha autonomia e, assim, torne-se empoderado à medida que faz parte ativamente do processo participativo). No entanto, para o desenvolvimento desses elementos é necessário que o ser humano seja conhecedor da sua realidade para tornar-se agente transformador da própria história (Zatti, 2007; Alves, 2009). Dessa forma, efetiva-se o conceito de práxis, que é uma mediação com a realidade, com vista em transformar e influenciar a si próprio, bem como o meio no qual se vive (Zatti, 2007; Alves, 2009).

O incentivo ao empoderamento e à autonomia, na infância, contribuirá para a formação de adultos proativos na comunidade e em ações sociais, já que existem períodos de sensibilidade durante a infância em que tipos específicos de aprendizado são realizados com maior facilidade; isso ocorre quando o cérebro requer um estímulo para consolidar algum costume contínuo (Chiesa, 2005).

Na Universidade Federal de Sergipe, Campus Lagarto, as Metodologias Ativas de Ensino Aprendizagem (MAEA) são utilizadas em todos os módulos. Na de Prática de Ensino na Comunidade (PEC), emprega-se a metodologia da problematização por meio do instrumento de reflexão, o Arco de Maguerez, em que todo processo de problematização começa com a observação crítica da realidade a fim de propor uma intervenção que transforme a realidade vivenciada (Schott, 2018). Assim, contribui-se para a construção de profissionais críticos, com perfil transformador e que modificam a realidade com maior criatividade e resolutividade (Fujita, Mecena, Carmona, \& Shimo, 2016).

A disciplina de PEC realiza atividades em conjunto com a comunidade, estimulando os discentes a utilizarem o conhecimento de sua realidade, por meio da territorialização, visitas, rodas de conversas, além da realização junto aos moradores, de um Planejamento Participativo, dentre eles o MB, com o objetivo de ajudar a comunidade na solução de problemas ou no desenvolvimento de suas potencialidades (Sá et al, 2007; Schott, 2018).

Nesse contexto, o objetivo deste estudo é relatar uma experiência de planejamento participativo com crianças, utilizando o Método Bambu para Promoção da Saúde.

\section{Metodologia}

A presente pesquisa trata-se de um relato de experiência de abordagem qualitativa a partir de uma intervenção realizada por meio de um Planejamento Participativo de efetivação de ações promotoras de saúde, executado com o público infantil, com a utilização do Método Bambu (Sá et al, 2007; Pereira, Shitsuka, Parreira \& Shitsuka, 2018). O público-alvo foi crianças de 5 a 8 anos de idade, pertencentes a uma microárea de saúde. As oficinas foram realizadas em uma comunidade rural, localizada a $18 \mathrm{~km}$ do centro do município de Lagarto (SE), em uma Escola Municipal de Ensino Fundamental. Os encontros foram conduzidos por discentes do primeiro ciclo/ano, dos oitos cursos de saúde da Universidade Federal de Sergipe (UFS), Campus Professor Antônio Garcia Filho, no módulo de Prática de Ensino na Comunidade I (PEC-I), com orientação da docente e do monitor. 
Realizou-se a observação participante e a construção de Diários de Campo (Marietto, 2018; Pezzato \& L'abbate, 2011). A observação foi realizada por meio do contato direto com o fenômeno observado para obtenção das informações sobre a realidade dos atores sociais em seus próprios contextos. Os diários foram construídos baseados em uma visita ao território para convidar a população a participar das ações e nas experiências das duas oficinas do Método Bambu. O diário de pesquisa possibilita conhecer a vivência cotidiana de campo, conforme feito na prática e não em normas pré-estabelecidas (Lourau, 1993).

As atividades foram realizadas nos meses de outubro e novembro de 2019, durante três momentos e com duração média de duas horas cada. No primeiro momento do MB, foi realizado o convite verbal e escrito, na escola e nas residências da microárea, para a realização da primeira oficina.

Nas semanas seguintes, foram executados os outros dois momentos do Método Bambu para realização de dez passos, descritos a seguir (Sá et al, 2007): (a) autoapresentação e dinâmica para criar laços e facilitar a convivência; (b) explanação do Método Bambu com ênfase na sua importância; (c) identificação das potencialidades da comunidade; (d) reconhecimento da realidade desejada pela comunidade; (e) elaboração de uma escala de prioridades, definindo os objetivos para atingir a comunidade desejada; (f) elaboração do mapa de prioridades, levando em consideração o interesse e o tempo para concretização; (g) planejamento das atividades com definição das responsabilidades de cada ator; (h) avaliação da oficina e expectativa para o próximo encontro; (i) acompanhamento do andamento das atividades; (j) finalização do projeto por meio da execução das atividades planejadas. Todas as atividades ocorreram em dia letivo, no turno vespertino e no pátio da escola. Os passos (a) a (h) aconteceram na primeira oficina e os passos (i) e (j) na segunda. Entre a primeira e a segunda oficina, houve um intervalo de 15 dias para execução das atividades planejadas.

\section{Resultados}

Participaram da primeira oficina do Bambu 4 crianças, com a faixa etária entre 6 e 8 anos, que cursavam do $1^{\circ}$ ao $4^{\circ}$ ano do Ensino Fundamental, sendo 3 do sexo feminino (75\%) e uma do sexo masculino (25\%). A segunda oficina contou com a participação de 26 crianças da mesma faixa etária anterior, e a maioria também pertencente ao sexo feminino ( $\mathrm{n}=15 ; 58 \%)$. Além dos alunos, na segunda oficina houve a participação de quatro professores da escola e o pai de uma aluna. Ressalta-se que a professora de PEC I, o monitor e 13 acadêmicos participaram de ambas oficinas, sendo 9 mulheres (69\%) e 4 homens $(31 \%)$.

Os resultados foram organizados segundo a ótica da observação participante, assistindo e interagindo com o grupo com uma constante aproximação e diálogo, partilhando as atividades, as ocasiões, os interesses e os afetos da comunidade, buscando-se colocar no lugar do outro, no seu ambiente social natural e articulando a teoria à prática.

De forma didática, os resultados foram divididos em três subtópicos com dois enfoques: dois subtópicos baseados nas oficinas do Método Bambu e o outro na contribuição do Método na Formação em Saúde.

\section{Primeira oficina do Método}

A primeira oficina foi realizada na semana seguinte ao convite, conforme pactuado. Neste dia, as aulas estavam suspensas devido à paralisação nacional no ensino público. Sendo um instrumento de mobilização importante em defesa dos direitos da educação, optou-se por não adiar a oficina, diante do compromisso já acertado com a comunidade. Havia também sido feita uma mobilização com carro de som, entrega de convites por escrito, articulações com vereador, agentes comunitários da localidade, e com lideranças locais. 
Houve a participação de apenas quatro crianças no primeiro encontro, sendo três do sexo feminino e uma do sexo masculino, com idade entre 6 e 8 anos. Esperávamos um maior número de pessoas, a fim de ser mais enriquecedor, no entanto, foi valorizada a participação de cada um, induzindo-os a conseguirem mais pessoas para o próximo encontro.

A oficina iniciou com um dos acadêmicos cantando e tocando algumas músicas. Logo após, os discentes de PEC apresentaram-se, e, posteriormente, houve a realização das etapas $(a-h)$, como segue descrito. Primeiramente, na autoapresentação e dinâmica (a), as crianças disseram seus nomes, idades e em quais séries escolares estavam. Falaram ainda sobre algo de que gostavam de fazer, como jogar bola e brincar. Na sequência, foi realizada uma dinâmica que funcionava da seguinte maneira: uma certa quantia de papel cortado em círculos foi dividida em dois montes iguais, uma delas foi dada às quatro crianças, que formaram um único grupo, e a outra foi dada a apenas um dos facilitadores. Feito isso, foi pedido para que ambos os grupos contassem quantos papéis tinham nos seus respectivos montes e quem acabasse primeiro seria o ganhador da brincadeira. As crianças, trabalhando em grupo, foram mais rápidas e venceram. Essa dinâmica serviu para demonstrar a importância do trabalho em grupo e da coletividade.

Em seguida, foi feita uma explanação do Método Bambu (b), relacionando algumas características do Bambuchinês, como seu crescimento subterrâneo invisível, sua flexibilidade, resiliência e versatilidade, estabelecendo paralelos com a vida em comunidade. Nessa vivência, buscou-se conhecer as experiências coletivas exitosas vivenciadas pelo grupo de crianças, na busca de identificar as potencialidades comunitárias (c). Dentre os relatos exitosos, citam-se: elaboração de um quadro de avisos feito pelas próprias crianças na sala de aula, no qual colocavam as datas dos aniversários, para que esses fossem lembrados e comemorados, e jogos e brincadeiras feitas nas aulas de Educação Física, promovendo a integração e o vínculo entre as crianças.

No momento seguinte, as crianças foram estimuladas a dizer qual a realidade desejada para a escola deles (d). Foram relatados os seguintes sonhos: "pintar a escola", "ter cobertura no pátio" (para proteger-se do sol), "ter um portão" (para que pudessem ter maior segurança), "ter cupcakes grátis na escola", e também pediram por mais brinquedos disponíveis, para que pudessem brincar nos intervalos das aulas. Após isso, elaborou-se a escala (e) e o mapa de prioridades (f) para escolha de um sonho. Conforme preconizado pelo Método, elegeu-se o sonho que mais crianças queriam, que demandava menos tempo para ser realizado e que dependia apenas delas mesmas para a sua efetivação. Dessa maneira, a fabricação de brinquedos foi o sonho escolhido, e, para que pudessem ser feitos pelas crianças, optou-se por construí-los a partir de materiais recicláveis.

Por conseguinte, procedeu-se o planejamento das atividades (g), com a definição das responsabilidades para cada ator. Determinou-se que os brinquedos a serem confeccionados seriam: jogo de boliche, bilboquês e "vai-e-vem". As crianças ficaram encarregadas de convidar os colegas para a segunda oficina, assim como o restante do corpo escolar e familiares, além de arrecadarem e levarem garrafas PET para o próximo encontro. Os facilitadores foram responsáveis por falar com a diretoria da escola a fim de que ela ajudasse na arrecadação de materiais recicláveis e auxiliasse na divulgação e participação da comunidade.

Por fim, realizou-se a avaliação da oficina (h). As crianças relataram ter gostado da experiência, ressaltando a oportunidade de escolher uma ação de importância coletiva e a possibilidade de criar seus próprios brinquedos, tendo em vista que a escola possuía escassa quantidade de brinquedos. Elas demonstraram entusiasmo e engajamento no projeto, pois estavam envolvidas em algo que traria diversão e união.

Destaca-se o quão importante foi, para as crianças, terem as suas opiniões consideradas de maneira séria, visto que foi de inteira responsabilidade delas, indivíduos entre 6 e 8 anos de idade, proporem desejos para a comunidade escolar realizar em conjunto. Nesse contexto, toda ideia que algum deles propunha era ponderada e debatida, colocavam-se os pontos positivos e negativos de cada uma, de maneira que elas entendessem o porquê de uma ideia ser mais exequível e interessante para a comunidade e outra não. Um exemplo foi o pedido de cupcakes grátis na escola. Quando essa ideia foi exposta, em nenhum 
momento os facilitadores a descartaram ou ignoraram, pelo contrário, ela foi debatida da mesma maneira que todas as outras, porém, conforme a conversa fluía de maneira simples e clara, as crianças começaram a entender que aquilo, de fato, não era tão importante, coletivamente, quanto as outras opções, a exemplo dos brinquedos recicláveis, que todos poderiam utilizar nos intervalos das aulas ou mesmo durante as aulas de Educação Física.

\section{Segunda oficina do Método Bambu}

$\mathrm{Na}$ semana interstício, antes da segunda oficina, foi mantido o contato com o diretor da escola para acompanhar o andamento das atividades (i) e a finalização do projeto (j).

Mesmo com o desafio da participação comunitária na mobilização para a segunda oficina, as crianças que estavam presentes na primeira tiveram o compromisso de relatar com os vizinhos e familiares a experiência vivenciada, e convidar para participar juntos da próxima reunião. Os facilitadores e o pai de uma das crianças (o único responsável que compareceu na escola), foram divididos em três grupos, em três salas de aula. Nesse dia, compareceram 26 crianças.

Cada grupo ficou responsável por orientar uma turma. Cada turma tinha em média 10 crianças. Conforme pactuado, elas trouxeram os materiais recicláveis e afirmaram ter convidado seus colegas, familiares e vizinhos. Dentro das três salas de aula, foram confeccionados diferentes tipos de brinquedos, feitos a partir de garrafas PET, barbante, fita adesiva, papel emborrachado, pistola de cola quente, dentre outros materiais.

Um resultado interessante foi ver como o valor e o respeito a um objeto mudam quando ele é feito pelas próprias mãos. Observou-se que todas as crianças, ao confeccionarem os brinquedos, perceberam a importância daquele trabalho. A atenção, interesse e cuidado eram notáveis. Percebeu-se também que, ao brincarem com os objetos manufaturados, tiveram muito cuidado e cautela para não quebrá-los ou danificá-los. Elas entenderam a importância do cuidado com algo que era de fabricação própria, que havia exigido esforço e dedicação. O comportamento das crianças demonstrou que elas se colocaram como sujeitos ativos nos seus próprios cotidianos e passaram a ser as protagonistas de sua própria diversão, não dependendo mais de terceiros.

\section{Formação em Saúde}

Os discentes puderam vivenciar diversas experiências que nunca acreditavam que poderiam presenciar ou fazer parte da vida acadêmica em um curso da área da saúde. Os Diários de Campo demonstraram as potencialidades da vivência do Método Bambu na Formação em Saúde. Selecionou-se trechos de diários de cinco acadêmicos, de forma intencional, para descrição do impacto do MB, no contexto das Metodologias Ativas em cursos da área da saúde. Os nomes de cada acadêmico foram codificados de forma alfanumérica.

Observou-se o desenvolvimento de habilidades e competências essenciais para a prática profissional, como a vivência de ações de Promoção de Saúde. Evidenciou-se, assim, alguns dos princípios do SUS, como a integralidade do cuidado e a participação popular, indo além de um modelo biomédico no qual o profissional da saúde trata apenas a doença do paciente, sem considerar os aspectos sociais, culturais e espirituais de cada um.

“[...] iniciamos a confecção dos brinquedos recicláveis. Durante a confecção, as crianças se empenharam bastante, sempre sob o olhar cuidadoso da professora responsável. Depois de muito cortar, colar, desenhar, acabamos de fazer os brinquedos e passamos a apreciar as crianças no intervalo se divertindo. Eu notei naquele dia um clima mais harmônico de algo novo e feliz, principalmente, quando saí da sala e vi os brinquedos confeccionados pelo outro grupo, me lembrou as verdadeiras brincadeiras da infância que hoje estão em escassez". (A1). 
Durante as oficinas do MB, os acadêmicos puderam desenvolver a capacidade de observação participante e escuta ativa, partilhando as atividades, as ocasiões, os interesses, os afetos da comunidade, e, a partir disso, colocarem em prática algumas habilidades como: empatia, simpatia, humildade, vínculo, bem como quebrar o paradigma existente de que as pessoas com nível superior, ou que possuem maior instrução escolar, são detentores de maior conhecimento.

"Pude aprender muito com essas visitas em campo, como lidar com as pessoas e como aprender com elas, nas coisas mais simples. Sou eternamente grato por essa oportunidade que o módulo da PEC I me proporcionou”. (A2)

"Mas também, podemos perceber que, com a aproximação dos alunos com a comunidade possibilitou um contato maior para com os moradores, conhecendo a realidade deles, e isso é essencial para o profissional que a todo momento irá interagir com um paciente”. (A3)

"No final, nos despedimos, pra mim foi um momento muito marcante, no qual eu pude sentir o carinho que eles sentiam por nós, e que sentiriam verdadeiramente nossa falta". (A2)

Outros dois pontos essenciais foram o estímulo ao trabalho em equipe e a organização de eventos. Os universitários foram orientados a cumprir alguns objetivos para que as tarefas fossem realizadas com sucesso. A capacidade de lidar com gerenciamento de conflitos existentes entre as divisões de tarefas também foi primordial para o desenvolvimento de habilidades na gestão de recursos, tanto materiais, quanto humanos.

"Antes de ir ao território, nós da turma subdividimos diversas tarefas para preparar um encontro organizado e proveitoso com a comunidade". (A1)

"Tínhamos tudo já organizado, as tabelas de potencialidades, experiências, as bolas para o quadro de prioridades, tudo que o método Bambu necessita para funcionar conforme seu manual”. (A2)

Por outro lado, a oportunidade de colocar em prática as teorias vistas em sala de aula foi de suma importância. Os diários puderam comprovar que os acadêmicos compreenderam os assuntos estudados, bem como conseguiram utilizá-los em diferentes contextos. Ademais, observou-se a apropriação contínua do que propõe a Metodologia Ativa de ensino do Campus.

"Isso nos fez ampliar nosso conhecimento sobre a territorialidade local, afinal, a territorialidade para Robert Sack (1986) é uma estratégia dos indivíduos ou grupo social para influenciar ou controlar pessoas, recursos, fenômenos e relações, delimitando e efetivando o controle sobre uma área". (A5)

"O menino não queria participar das brincadeiras, ele estava com uma expressão de tristeza e com tendência a querer ficar isolado. [...] a mulher explicou como era o ambiente familiar no qual ele estava inserido e como influenciava negativamente na vida dele. A partir dessa experiência é possível traçar uma relação com dois assuntos muito presentes na sociedade, cidadania e determinantes sociais em saúde (DSS). Estes influenciam a ocorrência de problemas de saúde e seus fatores de risco na população. [...] a criança participando de um ambiente familiar inadequado, existindo a presença da violência e não sendo respeitada, tem alta probabilidade de danificar a saúde psicológica, obter baixo rendimento escolar elou abandonar a escola, bem como posteriormente ser condicionado ao caminho da violência e criminalidade". (A4) 
Destaca-se, também, o desenvolvimento da capacidade de conseguir estabelecer comunicação efetiva, tendo em vista que o público era infantil, ou seja, não tão fácil de realizar a comunicação e de romper outras barreiras, tais como cultura e aspectos sociodemográficos. Por fim, a capacidade de estimular a motivação e o entusiasmo também foi executada durante todo o processo, especialmente na realização dos convites para as crianças participarem das oficinas do Bambu.

"Inicialmente eu senti uma dificuldade para trabalhar esse projeto com as crianças, principalmente por ser uma oficina que exige muito dos participantes, que cobra deles uma avaliação sobre seus papéis na comunidade e sobre as experiências comunitárias, por isso havia uma dificuldade com os pequenos. Todavia, aos poucos fomos adaptando o que podiamos para melhorar o funcionamento da oficina do bambu". (A2)

"Animando-os para irem na oficina que aconteceria na próxima semana. Como lemos no manual e discutimos em sala sobre a importância de sermos atenciosos e realmente instigar a participação comunitária, foi o que tentamos fazer ao máximo". (A2)

\section{Discussão}

Observou-se que, mesmo o número de participantes do estudo, contando com as crianças e com os acadêmicos, sendo relativamente pequeno, houve uma amostra coerente com os achados nacionais de prevalência feminina na educação, $58 \%$ dos participantes e $69 \%$ dos acadêmicos eram mulheres. Na educação pública superior, 53,8\% das matrículas efetuadas em 2014 eram referentes a pessoas do sexo feminino. Mais especificamente, 76,5\% das matrículas feitas em cursos da área da Saúde, no mesmo ano, pertenciam a mulheres. Esses números corroboram com os achados do presente estudo. No entanto, mesmo o sexo feminino sendo maioria na educação, no mercado de trabalho isso ainda não acontece, homens são muito mais presentes em cargos considerados de confiança, ainda que mulheres também estejam, no geral, mais preparadas, pois representam 55\% dos doutores titulados pela CAPES em 2016 (Barros \& Mourão, 2018). Esses números deixam claro que ainda há preconceito voltado à diferença de gênero no Brasil (Barros \& Mourão, 2018).

Outra questão importante foi o local de desenvolvimento dessa ação: a escola, pois a Promoção de Saúde, conciliada ao desenvolvimento pedagógico, tende a ser mais eficaz por associar-se ao conhecimento levado pelo aluno para fora dos limites escolares, principalmente para dentro de suas casas (Carvalho, 2015; Parente et al., 2020). No entanto, na realização da oficina, somente um responsável (pai de aluno) estava presente, o que foi um ponto negativo, visto que a relação mais íntima entre família e escola traz para a criança maior confiança em suas próprias capacidades e potencialidades, além de maior independência e maturidade (Oliveira \& Marinho-Araújo, 2010). Essa presença escassa de familiares no ambiente pedagógico pode ter sido causada pela paralisação escolar inesperada ocorrida naquele dia, ou então por uma relação já desgastada entre essas partes, provável fruto da falta de recursos que a escola tem a oferecer, sendo um deles a segurança, evidenciada, inclusive, pelas próprias crianças, devido à falta de um portão no local.

Além disso, durante o diálogo com os escolares sobre quais seriam os desejos do grupo, foi possível perceber uma preocupação com o bem-estar geral da escola, tanto com as pessoas que ali vivem, alunos e funcionários, quanto com o ambiente físico e suas carências. Alguns desejos como "pintar a escola", "ter cobertura no pátio" (para proteger-se do sol) e "ter um portão" (para que pudessem ficar mais seguras), mostraram noções de coletividade e de bem-estar geral, indo além do que muitos esperam dessa faixa etária. As crianças puderam entender a importância de ações altruístas, que visavam ao coletivo e ao bem da sociedade, e alegraram-se com isso, o que acontece quando existe o princípio da simpatia (Araldi, 2016).

As oficinas realizadas no projeto, mediante a utilização do Método Bambu, foram ações coletivas de Promoção à Saúde que proporcionam interação e reflexão sobre a realidade. Logo, observou-se que isso contribuiu para que os 
participantes pudessem fortalecer o sentimento de grupo/equipe, estimulando o exercício da cidadania com mais satisfação e estabelecendo uma união com os colegas. Esses resultados corroboram os objetivos do método, que são: promoção do sentimento de pertencimento e necessidade de identificar-se dentro do grupo social e do ambiente biofísico, isto é, apropriar-se do território ou, em outras palavras, vivenciar a territorialidade (Sá et al, 2007; Colin \& Pelicioni, 2018).

Outro ponto importante analisado, o despertar das potencialidades comunitárias, pode ser observado por meio da comparação do presente trabalho com um estudo que realizou uma intervenção de Promoção de Saúde feita com oito moradoras, com média de 35 anos, de um assentamento rural no estado de Pernambuco, no qual também foi utilizado o Método Bambu para avaliar o impacto dessa ação (Barros \& Ó, 2018). As participantes puderam reconhecer as potencialidades e fragilidades da comunidade, participar de oficinas com foco na Promoção de Saúde, demonstrar protagonismo no que se refere aos cuidados primários e responsabilização pelo ambiente, bem como no envolvimento em uma ação para a construção de um território saudável (Barros \& Ó, 2018). De maneira análoga, nas oficinas feitas com as crianças foram alcançados resultados semelhantes. Elas tiveram a oportunidade de lidar com situações nas quais eram requisitados princípios de autonomia, sustentabilidade e cooperação, a partir das necessidades e potencialidades comunitárias levantadas (Sá et al, 2007).

Em relação ao desenvolvimento da autonomia, especificamente na infância, nota-se que ela permeia o processo de desenvolvimento da criança em diversos ambientes, principalmente à medida que ela vai crescendo. Nesse sentido, acerca do desenvolvimento entre a heteronomia e autonomia, sabe-se que, quando a educação recebida pela criança é autoritária, contribui-se na formação e expressão da heteronomia, acarretando a dificuldade de formar "pessoas livres" (Pereira, 2006).

Consideram-se livres, pois, os indivíduos que possuem a capacidade de estabelecer o senso crítico e a coerência lógica em suas tomadas de decisões, sem necessitar, portanto, de uma autoridade para fazer tal regulação de escolhas (Nascimento, 2019). Dessa maneira, observou-se que a Metodologia, neste trabalho, contribuiu para o desenvolvimento da autonomia das crianças, haja vista que elas tiveram a oportunidade de opinar sobre seus desejos, distinguir e ter voz ativa sobre quais seriam as atividades que poderiam ser realizadas e quais seriam factíveis (Nascimento, 2019).

Tendo em vista todo o processo de desenvolvimento e conhecimento que foi partilhado com as crianças, por meio do Método Bambu, é possível estabelecer uma relação com a práxis. As crianças tiveram a oportunidade de desenvolver o senso crítico, a autonomia, o sentimento de territorialidade, dentre outros aspectos. Com isso, evidencia-se que elas puderam utilizarse do conhecimento e experiência realizada, estabelecendo, assim, a união entre a dialética e a prática, ou seja, a práxis, tornando-se, dessa forma, agentes transformadores da sua própria realidade (Alves, 2009).

A experiência das crianças, na construção dos brinquedos, demonstrou que elas entenderam a importância do cuidado com algo que era de fabricação própria, que havia exigido esforço e dedicação. Dessa maneira, elas se colocaram como sujeitos ativos do próprio cotidiano e passaram a ser as protagonistas de sua própria diversão, tendo seus valores reconhecidos e movendo-se rumo a uma transformação, não dependendo mais de terceiros (Moysés \& Franco, 2014). Segundo Freire, a conscientização dos indivíduos os insere no processo histórico e os estimula a buscar sua afirmação na sociedade (Freire, 1996).

Quando foi solicitado às crianças que expressassem seus sonhos para a comunidade, algumas ideias tiveram de ser descartadas, a exemplo do pedido de cobertura no pátio escolar, pois não atendiam a uma premissa importante do Método, que é a exequibilidade e a relação custo/benefício dos sonhos/desejos apresentados (Santana, Galvão, Costa, \& Tavares, 2016; Moysés \& Franco, 2014).

Caso, por exemplo, essas ideias tivessem sido levadas adiante, alguns dos resultados esperados poderiam não ser alcançados, como o estímulo à autoestima, ao empoderamento individual e ao coletivo (Moysés \& Franco, 2014), e principalmente à participação social, que é algo extremamente relevante para que a população possa ser ativa nas decisões 
sobre sua comunidade, nesse caso, decisões relacionadas à saúde, fazendo com que as políticas de Promoção à saúde sejam formuladas com mais equidade (Bortoli \& Kovaleski, 2019).

O presente estudo foi provedor, ainda, de muitos aspectos importantes na formação em saúde dos acadêmicos. Foi possível estabelecer vínculo, habilidade essencial que o profissional da APS deve ter, além de apropriar-se de uma diretriz da Política Nacional de Atenção Básica (PNAB) que é a territorialização e a importância da longitudinalidade do cuidado (Starfield, 2002; Kessler et al, 2019).

A longitudinalidade pressupõe que o profissional de saúde conheça o usuário como um ser singular, envolvendo o contexto familiar e social, além de questões relacionadas às patologias. O desenvolvimento crítico dos acadêmicos também foi perceptível, ocorreu à medida que o arcabouço teórico era construído e analisado junto com a observação da realidade durante a aplicação do MB, proporcionando um conhecimento das áreas de integração comunitária e saúde coletiva (Matos \& Caldeira, 2013). Ainda, a visualização de como se organiza a comunidade proporcionada pela imersão em sua dinâmica real colaborou para que a proposta da PEC-I fosse contemplada e gerou práticas sustentáveis e estímulo da comunidade para a participação social, característica essencial da Saúde Pública.

Outro aspecto importante veio da oportunidade de os acadêmicos estarem à frente do projeto, lidando com problemas comunitários e particulares que surgiam. Essas experiências adquiridas foram relevantes para a formação dos discentes, já que há uma grande discussão em torno da preparação de futuros profissionais da saúde mais humanizados e preparados para lidar com a realidade social, prestando serviços não somente no cuidado com a saúde, mas também no fortalecimento da cidadania nos territórios trabalhados (Schott, 2018).

Essa foi uma grande oportunidade para que os facilitadores pudessem ter uma experiência de intervenção que acompanha o modelo de reestruturação da atenção à saúde. Eles puderam compreender e lidar com a população de uma maneira completa, por meio de uma ação fundamentada nos Determinantes Sociais de Saúde (DSS), abrangendo, assim, os lados emocional, social e físico dessas pessoas (Prado \& Santos, 2018). Essa percepção permite inferir que a realização do Método Bambu, com a participação dos profissionais da saúde, no contexto da APS, pode ser uma estratégia facilitadora para aumentar o vínculo e a satisfação dos usuários. As oficinas podem oferecer uma melhor compreensão de suas fragilidades e potencialidades, auxiliando, dessa maneira, na autoafirmação como seres singulares, fortalecendo vínculos, quebrando paradigmas e indo além do que propõe o modelo biomédico hegemônico (Heidemann et al, 2018).

\section{Considerações Finais}

Por meio das experiências vivenciadas, foi possível desenvolver habilidades necessárias para elaboração de atividades de educação e lazer, adequando os anseios de seus componentes e, assim, favorecendo a participação destes em todo o processo. A experiência do Método Bambu ainda evidenciou o conhecimento da realidade a ser trabalhada e a realização de um coletivo fundamentado na empatia, no diálogo e nas potencialidades de seus participantes e de sua comunidade.

A evolução gradual da participação no grupo pelas crianças, abandonando a timidez inicial e aderindo à livre expressão, à autonomia e à liberdade de escolhas, pode ser resultado da aquisição de conhecimentos e do empoderamento dessas crianças ao longo das duas oficinas realizadas, engrandecendo-as por meio da participação para estarem aptas a tomarem decisões favoráveis ao seu dia a dia.

Ficou evidente que atividades de Promoção de Saúde que envolvem a participação da população exigem muito mais do que simples encontros e rodas de conversa. É necessário que haja uma cooperação entre as partes, tornando a troca de saberes horizontalizada. Quando isso ocorre, essa troca torna-se democrática e o resultado é a valorização das potencialidades e habilidades de cada pessoa. A partir disso, a comunidade ou o grupo trabalhado passa a ter uma convivência mais saudável e benéfica, contribuindo para uma sociedade mais humanizada, mais sustentável e assim mais saudável. 
Diante essa realidade, cabe destacar a necessidade de novos estudos para compreender os fatores que potencializam a utilização do Método Bambu para a promoção do empoderamento e seus impactos na condição de saúde do indivíduo e da comunidade, ademais, compreender a dinâmica e o impacto da atuação da universidade como agente colaboradora desse processo de empoderamento no público infantojuvenil é imprescindível para a melhoria de ações e ampliação do conceito de saúde e autonomia em outras comunidades.

\section{Referências}

Alves, L. H. S. (2009). Pedagogia da Autonomia: saberes necessários à prática educativa. Nucleus, 16(2): 97-100.

Araldi, C. L. (2016). Nietzcshe e Paul Rée: Acerca da existência de impulsos altruístas. Cad. Nietzsche, 37(1): 71-87.

Barros, M. B. S. C. \& Ó, D. M. S. O. (2018). "Conhecer os Desejos da Terra”: intervenção de promoção à saúde em um assentamento rural. Revista APS, 21(3): 365-374.

Barros, S. C. V. \& Mourão, L. (2018) Panorama da participação feminina na educação superior, no mercado de trabalho e na sociedade. Psicologia \& Sociedade, 30: e174090.

Bortoli, F. R. \& Kovaleski, D. F. (2019). Effectiveness of participation of a municipal health council in the Brazilian South region. Saúde Debate, 43(123): $1168-1180$.

Carvalho, F. F. B. (2015). A saúde vai à escola: a promoção da saúde em práticas pedagógicas. Physis, 25(4):1207-1227.

Campos, G. W. S., Minayo, M. C. S., Akerman, M., Drumond Júnior, M., Carvalho, Y.M. (2006). Tratado de Saúde Coletiva. Hucitec, Editora Fiocruz.

Chiesa, A. M. (2005). Autonomia e resiliência: categorias para o fortalecimento da intervenção na atenção básica na perspectiva da Promoção da Saúde [tese]. São Paulo: Escola de Enfermagem da Universidade de São Paulo.

Colin, E. C. S. \& Pelicioni, M. C. F. (2018). Territorialidade, desenvolvimento local e promoção da saúde: estudo de caso em uma vila histórica de Santo André, São Paulo. Saúde Sociedade, 27(4): 1246-1260.

Declaração de Alma Ata sobre Cuidados Primários. (1978). http://bvsms.saude.gov.br/bvs/publicacoes/declaracao_alma_ata.pdf

Duarte, E., Eble, L. J. \& Garcia, L. P. (2018). 30 years of the Brazilian National Health System. Epidemiol. Serv. Saúde, 27(1): e00100018.

Freire, P. (1996). Pedagogia da autonomia: saberes necessários à prática educativa. (25a ed.), Paz e Terra.

Fujita, J. A. L. M., Mecena, E. H., Carmona, E. V., Shimo, A. K. K. (2016). Uso da metodologia da problematização com o Arco de Maguerez no ensino sobre brinquedo terapêutico. RPE, 29(1): 229-58.

Heidemann, I. T. S. B., Cypriano, C. C., Gastaldo, D., Jackson, S., Rocha, C.G., Fagundes, E. (2018). Estudo comparativo de práticas de promoção da saúde na atenção primária em Florianópolis, Santa Catarina, Brasil e Toronto, Ontário, Canadá. Cad Saúde Pública, 34(4), e00214516.

Kessler, M., Lima, S. B. S., Weiller, T. H., Lopes, L. F. D., Ferraz, L., Eberhardt, T. D., ..., Trindade, L. L. (2019). Longitudinality of Primary Health Care: an evaluation from the perspective of users. Acta paul. Enfermagem, 32(2): 186-193.

Lourau, R. (1993). Análise Institucional e Práticas de Pesquisa. Rio de Janeiro: EdUERJ.

Marietto, M. (2018). Observação Participante e Não Participante: Contextualização Teórica e Sugestão de Roteiro para Aplicação dos Métodos. Iberoamerican Journal Of Strategic Management, 17(4): 05-18.

Matos, F. V. \& Caldeira, A. P. (2013) Interação Comunitária e Planejamento Participativo no Ensino Médio. Rev. bras. educ. med., 37(3): 434-440.

Moysés, S. T. \& Franco, S. R. (2014). Planos locais de promoção da saúde: intersetorialidade(s) construída(s) no território. Ciênc. saúde coletiva, 19(11): 4323-4330.

Nascimento, J. L. A. (2019). A construção da autonomia na educação infantil [Monografia]. Guarabira: Universidade Estadual da Paraíba.

Oliveira, C. B. E. \& Marinho-Araújo, C. M. (2010). A relação família-escola: intersecções e desafios. Estudos de Psicologia, 27(1): 99-108.

Parente, F.S., Oliveira, R. C. M., Santos, L. C. M., Tsukimata, M. Y., Silva, J. M. R., Sacramento, R. C., Lopes, L. J. S. (2020). Health Education: a socioeducational tool for health promotion for children in a public school in Belém do Pará, Brazil. Research, Society and Development, 9(7): 1-13.

Pereira, R. L. (2006) O papel da educação infantil na construção da autonomia moral: uma revisão de literatura [Monografia]. Porto Alegre: Universidade Federal do Rio Grande do Sul.

Pereira, A. S., Shitsuka, D. M., Parreira, F. J., Shitsuka, R. (2018). Metodologia da pesquisa científica. UFSM.

Pezzato, L. M. \& L'abbate, S. (2011). O uso de diários como ferramenta de intervenção da Análise Institucional: potencializando reflexões no cotidiano da Saúde Bucal Coletiva. Physis, 21(4): 1297-1314. 
Research, Society and Development, v. 10, n. 2, e42710212709, 2021

(CC BY 4.0) | ISSN 2525-3409 | DOI: http://dx.doi.org/10.33448/rsd-v10i2.12709

Prado, N. M. B. L. \& Santos, A. M. (2018). Promoção da saúde na Atenção Primária à Saúde: sistematização de desafios e estratégias intersetoriais. Saúde Debate; 42(1), 379-395.

Sá, R. F., Araújo, J. A., Freire, M. S. M., Senna Salles, R., Chuma, J., Royama, H., Yuasa, M., Yamamoto, S., Menezes Filho, A. (2007). Manual do método Bambu - construindo municípios saudáveis. Recife: Editora Universitária UFPE.

Santana, C. S., Galvão, G. G., Costa, P. M. C., Tavares, M. F. L. (2016). Employment and income generation as a Health Promotion Strategy: the case of women submitted to mastectomy in Nova Iguaçu, RJ, Brazil. Ciênc. saúde coletiva, 21(6): 1921-1930.

Schott, M. (2018). Teaching-service articulation: strategy for health graduation and permanent education. REFACS, 6(2): 264-268.

Starfield, B. (1994). Is primary care essential? Lancet, 344(8930): 1129-33.

Starfield, B. (2002). Atenção primária: equilíbrio entre necessidades de saúde, serviços e tecnologia. Brasília: UNESCO, Ministério da Saúde.

Teixeira, M. G., Costa, M. C. N., Carmo, E. H., Oliveira, W. K., Penna, G. O. (2018) Health surveillance at the SUS: development, effects and perspectives. Ciênc. saúde coletiva; 23(6): 1811-1818.

Zatti, V. (2007). Autonomia e Educação em Immanuel Kant \& Paulo Freire. EDIPUCRS. 